\title{
Cumbersome Institutional Credit for SMEs: The Indian Experience
}

\author{
Dr. Santhosh Kumar S. \\ Associate Professor, P.G. and Research Department of Commerce, St. Peter's College, Kolenchery, Ernakulam, \\ Kerala. Pin. 682311
}

\begin{abstract}
Industrial finance institutions, often called the development financial institutions (DFIs) were set up at the national level and at the State level with a view of quickening the pace of industrialisation in India. These lending institutions were operating in a regulated and protective regime upto the introduction of economic reforms in the country. With the deregulation of the financial system since 1991, they have been finding their traditional business fast disappearing. They were deprived of the protective climate in which they operated for long, and their access to concessional sources of funds was stopped. They came to be forced to compete with commercial banks whose cost of funds was lower than that of DFIs. This, in turn, adversely affected their fresh business, as the demand for loans has come down sharply. The Kerala Financial Corporation (KFC) and Kerala State Industrial Development Corporation (KSIDC) are the two State-owned financial institutions set up primarily for providing loans to the industrial sector in Kerala. Being ISO-certified institutions, these Corporations demand that their loan operations have easy access and hassle-free procedures, excellent and friendly service. Notwithstanding these claims of the Corporations, the procedural delays, unnecessary formalities and non-viable terms and conditions involved in lending operations have been receiving criticisms from the assisted units, researchers and other interested parties. The paper, a part of the research study about the institutions, attempts to evaluate the procedures and terms and conditions of lending by the financial institutions to the industrial sector in India specifying the State of Kerala as a case.

Key Words:- Financial Institutions - Development banks - Term loans - Industrial finance - Industrial development - Kerala financial corporation - KFC - Financial structure - Capital structure - Industrial finance institutions - Development financial institutions - Financial institutions in Kerala
\end{abstract}

\section{Introduction}

The institutional source of finance for industry in India is a post-independence phenomenon. The widespread demand for a special machinery to finance industry during the pre- independence era, and the recommendations of the different committees which probed the financing problems of industries, led to the formation of specialised institutions for providing finance to Indian industry. These institutions, often called the development financial institutions (DFIs) or development banks in India, were set up at the national level and at the State level (not at one stretch) with a view of quickening the pace of industrialisation. The present structure of institutional finance in India comprises of six All India Development Banks (AIDBs), 28 State Industrial Development Corporations (SIDCs), 18 State Financial Corporations (SFCs), and the North Eastern Development Financial Corporation (NEDFC). They have been providing project finance and other forms of industrial finance as term-loans. These lending institutions were operating in a regulated and protective regime upto the introduction of economic reforms in the country. With the deregulation of the financial system since 1991, they have been finding their traditional business fast disappearing. After the reforms, these development banks were deprived of the protective climate in which they operated for long, and their access to concessional sources of funds was stopped. They came to be forced to compete with commercial banks whose cost of funds was lower than that of DFIs (Pathak, 2003, p. 345; Patil, 2001, p. 351; Mohan, 2004, p.319; Datar 1999, p. 1640). This, in turn, adversely affected their fresh business, as the demand for loans has come down sharply. The shares of AIDBs in the total sanctions and disbursements have declined noticeably. The sanctions and disbursements of SIDCs and SFCs are continuing their downward slide. This dismal picture is accentuated not only by the unfavourable situation brought in by the reforms measures but also by the operational vagaries of these institutions in general. The present paper is a part of a research study and attempts to evaluate the procedures and terms and conditions of lending by these financial institutions to the industrial sector specifying the State of Kerala as a case.

\section{Back Ground of Study}

The Kerala Financial Corporation (KFC) and Kerala State Industrial Development Corporation (KSIDC) hereinafter referred as State Financial Institutions or SFIs or Corporations are the two State-owned financial institutions set up primarily for providing loans to the industrial sector in Kerala. Since their inception 
(KFC in 1953 and KSIDC in 1961), they have been extending term loans and other forms of assistance to build up healthy industrialisation in the State. Earlier research studies and intellectual attempts probing the details of operations of these Corporations have raised doubts regarding the procedural complications in availing assistance, the unviable terms and conditions in loan agreement and the poor performance of the units assisted by these Corporations (Koshy, 1992; Ganesh, 1993; Jestus 1996). All these studies were taken up before the economic reforms in 1991 or in the very early years of the reform process. But, these Corporations hold that, since reforms they have been more equipped than earlier to provide uninterrupted assistance to the industry and to meet the emerging challenges that have taken place after the reforms $\left(\mathrm{KFC}_{(\mathrm{a})}, 2005\right.$, pp. 6-7; $\mathrm{KSIDC}_{(\mathrm{a})}, 2003$, p. 4). However, the lending performances of these Corporations during the post-reform period, as revealed by their Annual Reports, are not creditable. The growth in the number of loan applications sanctioned by the KFC during the ten-year period, 1995-96 to 2004-05, shows a negative Compounded Annual Growth Rate (CAGR) of 9.77 per cent, with an average year by year decline of 301 applications. The amount of sanctions and disbursements of loans by the KFC for the above period shows a negative CAGR of 3 per cent and 2.7per cent respectively. The asset quality (advances) of the KFC is very poor, with 52.36per cent of it as Non Performing Assets (NPAs) (on March 2005) and the accumulated loss of the Corporation amounts to Rs.70.82 crores (March 2005) against the paid up capital of Rs.155.06 crores $\left(\mathrm{KFC}_{(\mathrm{a})}\right.$, 2005). The picture of the KSIDC is also not different. The loan sanctions of the KSIDC against the medium and large-scale industries during 1995-96 to 2004-05 show a negative CAGR of 0.60per cent and the disbursements during the same period show a negative CAGR of 2.23per cent. The accumulated loss of the Corporation in March 2005 amounted to Rs. 9.16 crores against the total paid up capital of Rs. 294.74 crores on the date. The asset quality of the Corporation was also poor with 63.4per cent NPAs $\left(\mathrm{KSIDC}_{(\mathrm{b})}, 2005\right)$.

Being state-owned agencies formed for industrial promotion in the region, they are expected to extend timely financial assistance to entrepreneurs through simplified procedures and viable terms and conditions to the satisfaction of the entrepreneurs. The KFC caters to the needs of small and medium scale industries, while the KSIDC offers assistance primarily to medium scale industries. These institutions are equipped with a team of personnel specialised in loan operations to cater to the variegated needs of the entrepreneurs. Being ISOcertified institutions, these Corporations demand that their loan operations have easy access and hassle-free procedures, excellent and friendly service. Notwithstanding these claims of the Corporations, the procedural delays, unnecessary formalities and non-viable terms and conditions involved in lending operations have been receiving criticisms from the assisted units, researchers and other interested parties. It is in these contexts the research study advanced probing into the different aspects of institutional lending in Kerala.

\section{Study Setting and Methodology}

The study was empirical in nature covering SFIs assisted units in all the districts of Kerala, India. Altogether, 17547 units, which availed loans upto 31st March 2006, constituted the population of the study. A sample of 500 units was selected on random method (Table 1). The evaluation of procedures and terms and conditions of lending by the SFIs, is done based on the responses of the SFIs-assisted units collected on a fivepoint scale. The views of the Corporations on relevant points are also incorporated, wherever necessary, to arrive at meaningful inferences on the variables used for evaluation. The seven variables considered for evaluation of procedures are, support for project planning, processing time of application, formalities stipulated, processing fee, time for project appraisal and sanction, time for documentation and disbursement and attitude of officials. The terms and conditions imposed for seeking assistance are also evaluated using another set of seven variables such as promoters' share, security requirement, rate of interest, penalisation for default, pre-closure premium, restriction in second charge creation and repayment and recovery norms. The reliability of the selected variables for assessing the procedures and terms and conditions of lending by the SFIs was found to be 0.698 (Cronbach's Alpha - Nunnally, 1978). Student's t test and Analysis of Variance (ANOVA) were used to analyse the average values of different variables among different sections of the data. Error Bars at ninety-five per cent confidence level are used to test the average values of the variables industry-wise.

Table 1. Profile of respondent units - industry-wise

\begin{tabular}{|l|l|c|c|}
\hline \multicolumn{1}{|c|}{ Nature of Industry } & $\begin{array}{c}\text { No. of } \\
\text { Units }\end{array}$ & $\begin{array}{c}\% \text { to } \\
\text { Total }\end{array}$ \\
\hline \multicolumn{2}{|l|}{ A. Manufacturing Sector } & 30 & 6.0 \\
\hline 1 & Mining \& Quarrying & 7 & 1.4 \\
\hline 2 & Textiles & 55 & 11.0 \\
\hline 3 & Food products & 38 & 7.6 \\
\hline 4 & Wood \& Wood Products &
\end{tabular}


Cumbersome Institutional Credit for SMEs: The Indian Experience

\begin{tabular}{|l|l|c|c|}
\hline 5 & Paper \& Paper products & 9 & 1.8 \\
\hline 6 & Chemicals & 10 & 2.0 \\
\hline 7 & Rubber \& Plastics & 70 & 14.0 \\
\hline 8 & Basic Metals \& Metal Products & 14 & 2.8 \\
\hline 9 & Tiles \& Bricks & 48 & 9.6 \\
\hline 10 & Other manufactures & 35 & 7.0 \\
\hline \multicolumn{2}{|c|}{ Total (A) } & 316 & 63.2 \\
\hline B. Service Sector & 115 & 23.0 \\
\hline 11 & Services & 69 & 13.8 \\
\hline 12 & Other services & 184 & 36.8 \\
\hline Total (B) Grant Total (A+B) & 500 & 100 \\
\hline \multicolumn{2}{|c|}{} \\
\hline
\end{tabular}

Source: Primary data

\section{- Hypotheses}

1. The procedures adopted by the SFIs for releasing loans have been causing dissatisfaction to the industrial sector in the State.

2. The terms and conditions imposed by the SFIs are unfavourable to the industrial sector in the State.

\section{- Operational Definitions}

1. Dissatisfaction to the Industrial Sector: The condition that the mean value of the actual score of the views of the industrial units regarding the procedures of the SFIs for providing loans being lower than the central value of the minimum and maximum expected score on a five-point scale is taken to be dissatisfaction of industrial sector towards the procedures of the SFIs.

2. Unfavourable to the Industrial Sector: The condition that the mean value of the actual score of the views of the industrial units regarding the terms and conditions imposed by the SFIs for providing loans being lower than the central value of the minimum and maximum expected score on a five-point is taken to be unfavourable to the industrial sector.

\section{Results and Discussion}

The results of the study are discussed under two sections a) Procedures of Lending and b) Terms and Conditions of Lending.

\section{Section A: Procedures of Lending}

As part of evaluating the total procedures involved in lending the summated scores of procedures (hereinafter called procedures score) for the seven dependent variables were calculated (Table 2). The minimum possible value of procedures score was seven, the maximum was thirty five and the central value was twenty one. The error bars at ninety-five per cent confidence level (Fig. 1) comparing the total score of the seven variables industry-wise with the total central value of the seven variables (21) indicate that the hypothesis developed for the study, the procedures adopted by the SFIs for releasing loans have been causing dissatisfaction to the industrial sector in the State, stands accepted. Isolating the scores of the individual variables, attitude officials of the Corporations alone shows a significantly higher score above the central value. No significant differences were found industry-wise with regard to the views on procedures (Table 3 ).

Table 2 Score of views on procedures

\begin{tabular}{|c|l|c|c|c|}
\hline $\begin{array}{c}\text { Sl. } \\
\text { No. }\end{array}$ & \multicolumn{1}{|c|}{ Criteria } & $\begin{array}{c}\text { Central } \\
\text { value }\end{array}$ & $\begin{array}{c}\text { Actual } \\
\text { Score }\end{array}$ & Rank \\
\hline 1 & Support for Project Planning & 3 & 1.078 & 7 \\
\hline 2 & Processing Time of Application & 3 & 2.876 & 4 \\
\hline 3 & Formalities Stipulated & 3 & 2.664 & 6 \\
\hline 4 & Processing Fee & 3 & 2.776 & 5 \\
\hline 5 & Time for Project Appraisal and Sanction & 3 & 2.952 & 2 \\
\hline 6 & Time for Documentation and Disbursement & 3 & 2.886 & 3 \\
\hline 7 & Attitude of Officials & 3 & 3.522 & 1 \\
\hline \multicolumn{2}{|c|}{ Total } & 21 & 18.754 & \\
\hline
\end{tabular}

Source: Primary data 
Figure 1. Error bars of procedure score-industry wise

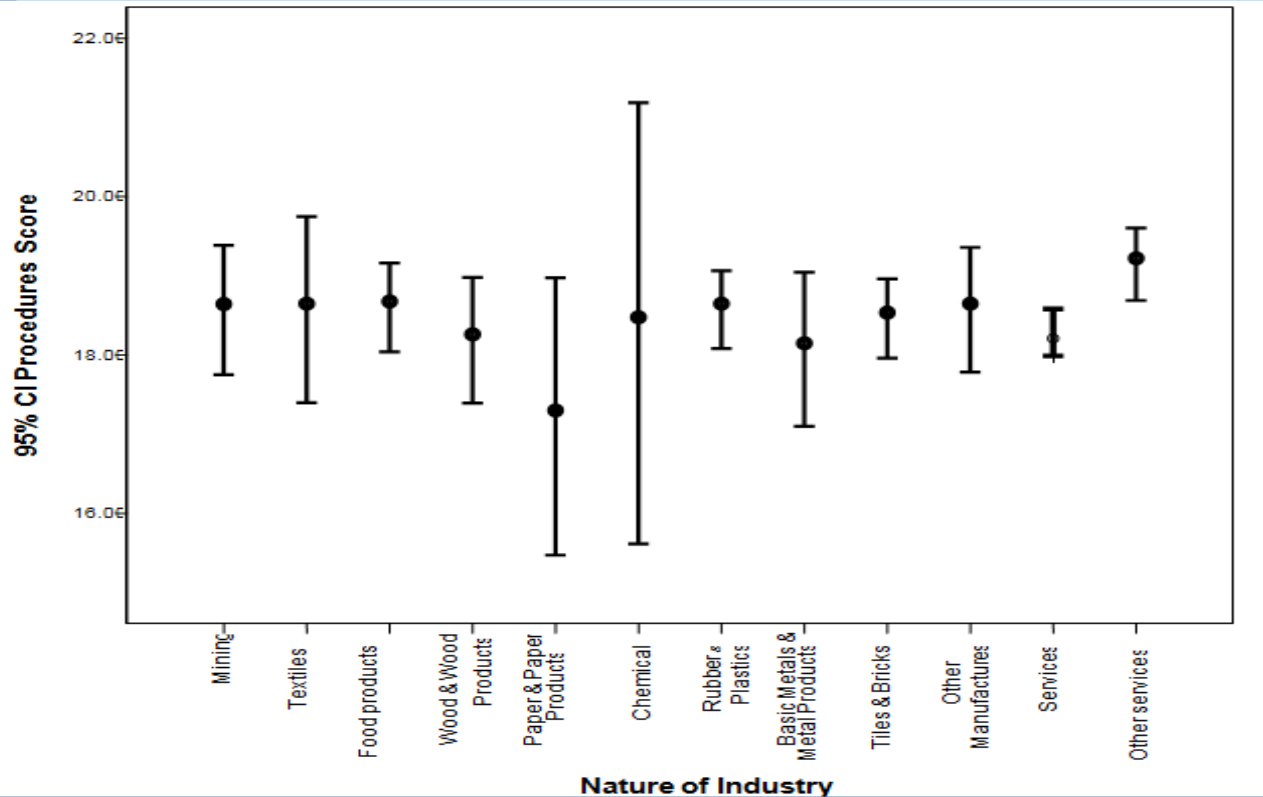

Table 3 ANOVA - Procedures score (industry-wise)

\begin{tabular}{|c|c|c|c|c|c|}
\hline Source of Variation & $\begin{array}{c}\text { Sum of } \\
\text { Squares }\end{array}$ & df & $\begin{array}{c}\text { Mean } \\
\text { Square }\end{array}$ & F & P-value \\
\hline Between Groups & 60.879 & 11 & 5.534 & 1.375 & $.181^{*}$ \\
\hline Within Groups & 1964.049 & 488 & 4.025 & & \\
\hline Total & 2024.928 & 499 & & & \\
\hline
\end{tabular}

*No Significant difference

\section{Support for Project Planning}

The support of financial institutions (FIs) in project planning of the prospective entrepreneurs usually helps to make the planning process more intelligent. Moreover, institutional support in project planning may harden the responsibility of these institutions to move along with the further proceedings on viable projects so as to make the projects materialise without delay. The support for project planning, prior to financial assistance, can be ensured only through an organised mechanism created for the purpose. Remarkably, the SFIs have been associating themselves with the process of project planning of their prospective or current customers through the Business Development Section/Project Division in their respective offices. In brief, the active support of these institutions in the project planning of the approaching entrepreneurs could help to suitably modify the proposal to a viable business idea, if necessary, for seeking assistance. Therefore, support for project planning by these institutions to the approaching entrepreneurs is inevitable to bring healthy industrialisation and to make the lending procedures hazzle-free. The responses of the selected units in this regard are pathetic with the lowest rank among the seven criteria of evaluation of procedures (score 1.078, rank 7). The views of the significant majority of the units, deeply discounting the services of the SFIs in project planning, hint the malfunctioning of the mechanism at least to the extent of providing support for project planning.

\section{Processing Time of Application}

Processing time of loan applications elucidate the time span involved in the submission of loan application by the promoter to the Corporations' decision to accept or reject the said application after preliminary screening. Quick processing of applications by the institutions is inevitable for avoiding any delay in considering the proposal for detailed project appraisal after preliminary screening. The actual score of the responses of the selected units regarding processing time is significantly lower than the central value of the expected score (score 2.876, rank 4). The institutional delays in processing of applications are justified by the authorities blaming the promoters on their slip-ups in the submission of applications. The reported delay in processing time is to be viewed seriously as it is a demoting factor for the prospective entrepreneurs.

\section{Formalities Stipulated}

The formalities stipulated by the Corporations in extending loan assistance comprise the elaborate courses of action the promoter has to do in connection with the preparation and submission of a complete loan 
application along with the various documents, preliminary appraisal, supply of information on queries made by the Corporations, project appraisal, sanctioning of loan, execution of loan agreement, provision of security, disbursement of loan, availing investment subsidy and repayment. The ease with which the various formalities involved (to be done by the applicant) in the loaning process can be done by the applicant, is an index of the simplicity of the various formalities involved in connection with the lending procedures of the Corporations. The simplification and minimisation of the formalities in the lending process by the SFIs are to be undertaken as a continuous process, wherein efforts to modify, improve and validate the formalities from time to time, in a way making them more customer-friendly are inevitable. Regarding the formalities involved, the Corporations were of the view that there were more or less uniform formalities for availing loans, irrespective of the nature of the industry, the size of investment, and the scheme of assistance. The Corporations being ISO-certified institutions claim that, all the formalities involved are standardised, avoiding duplication, combining individual formalities to the extent possible and simplifying the method of complying with the formalities. They were of the view that the formalities might get complicated due to handicaps in the project report submitted, abnormal subjectivity in the estimation of future income from the proposed unit, vagaries in the title of the security offered, insufficiency of security offered, delay in asset creation in proportion to disbursements already done, delay in committing promoter's capital, and so on. However, the views of the assisted units in this regard stand opposed to the claims of the Corporations. The summated score of the views of the units on formalities stipulated figures 2.664 (rank 6) and is significantly lower than the central value of the expected score.

\section{Processing Fee}

The service charge levied by the Corporations as fee for the processing and sanctioning of loan applications is compulsory for promoters. The processing fee is usually charged as a certain percentage of the amount of the loan applied for, with or without a maximum ceiling. References to the practice of charging processing fee by the SFIs reveal that they usually levy a certain percentage of loan applied for, as processing fee with a ceiling limit. Therefore, naturally, when the amount of assistance sought increases, the processing fee also increases proportionately up to the ceiling and then it remains constant. For the last many years, the Corporations have levied 0.5 per cent of the assistance sought as processing fee. Comparing the processing fee of Rs. 500 for a loan application amounting to Rs. 1 lakh, with the processing fee of Rs. 50, 000 for a loan application amounting to Rs. 100 lakh, the larger units have to shoulder an additional burden of Rs. 49, 500 towards processing fee. Against this anomalous situation, the larger units have presented a strong case against this burden they have to face at the inception stage. Moreover, these units are of the view that irrespective of the size of assistance sought, the job of the Corporations is more or less the same with regard to the processing involved in sanctions and disbursements. Again, they feel that this huge amount spent as processing fee during the promotion stage is non-productive in nature with zero ability to contribute towards profitability but necessitating write-offs from future profits. The actual score of the views of the assisted units endorses the dissatisfaction of the units (score 2.776, rank 5). A careful revision of the processing fee structure of the Corporations can be the simple step to overcome these charges.

\section{Project Appraisal and Sanction}

A project which is qualified in the preliminary screening is put to a detailed project appraisal (after formally accepting the application) to decide upon the project feasibility and eligibility for sanction. Only those projects which are found viable in the detailed project appraisal are usually recommended for sanctioning loan assistance. The time span involved in between the acceptance of loan applications after preliminary screening by the Corporations and the sanctioning of the assistance can be reckoned as the time taken for project appraisal and sanction. The KFC claims that, when an application for loan assistance is accepted after necessary preliminary screening, it can be given the sanction within thirty days of the acceptance of the application, if it is found to be a viable project, through a detailed project appraisal $\left(\mathrm{KFC}_{(\mathrm{b})}, 2005\right.$, pp. 1-10). The KSIDC has not announced a time limit for the said process as done by the KFC, but the average time in this regard as learnt from the discussions with the officials, is two months (the KSIDC deals with larger projects involving higher sanctions). The average score of the ratings of the units (score 2.952, rank 2) with regard to the sanctioning time of credit by the Corporations (not significantly lower than central value of expected score) approves to a certain extend the claims of the Corporations regarding appraisal and sanctioning time of assistance.

\section{Documentation and Disbursements}

The timely disbursement of loans, after sufficient documentation, is essential for the well-timed and successful completion of projects. Abnormal delay in disbursement can cause cost overrun, delay in commissioning the project and other losses connected with the extension of the project. The time lag between actual disbursement of the assistance by the SFIs (at each stage) and the fulfilment of the various requirements by the borrower (at each stage) is deemed to be the time taken for the disbursement of assistance. The actual 
score of the views of the assisted units in this regard is significantly lower than central value of the expected score (score 2.886, rank 3). As the sanctioned amounts of loans are disbursed by the Corporations in instalments, such disbursements demand timely fulfilment of certain disbursement conditions as agreed upon by the units with the SFIs. Timely disbursements can be ensured by the units only if such conditions are fulfilled to the reasonable satisfaction of the Corporations. Some of the relevant conditions in this regard are the stage-wise commitment of promoters' capital as agreed upon, progress in assets creation as agreed upon, and the general progress of the project as planned. The SFIs were of the view that, the reported delays in the case of some of the units might be due to the hold-up in fulfilling any one or more of the above conditions. Anyhow, regarding disbursement of sanctions, the SFIs should try to avoid even a single anomaly on account of negligence from their part. Similarly, timely accomplishment of those pre-disbursement conditions as agreed upon by the loanees should also be ensured to the satisfaction of the SFIs, before claiming each disbursement. Regarding disbursement time, it is not wise to comment simply by reckoning the number of weeks or number of months involved for disbursement. In most of the cases, the disbursements are made in instalments, depending upon the need of the promoter, extent of assets creation at different stages, and the general progress of the project. The expected time span of disbursement to the promoter may vary from industry to industry and size to size.

\section{Attitude of Official}

The attitude of officials (the behavioural reflections) of the SFIs plays a noteworthy role in making the loaning procedure friendly, avoiding unnecessary strains to the borrowers. Borrowers, being in the front of setting up an undertaking or otherwise, are exposed to many kinds of tensions. Therefore, positive and friendly attitude of officials throughout the entire procedure of loans has a big hand in tuning it hassle free. The SFIs being ISO-certified institutions, they claim friendly approach and relaxed formalities on their part to make available loan assistance within the minimum possible time and formalities. The views of the loanees endorse the claim of the SFIs in this regard. The mean score of the views of the units is the highest among others and is significantly higher than the central value of the expected score (score 3.522, rank 1).

\section{Section B: Terms and Condition of Lending}

The terms and conditions of lending of the SFIs are the specifications as part of the loan agreement which the lender and the borrower have to comply with, during the tenure of the agreement. It mainly comprises the various stipulations regarding rate of interest, security requirements, promoters' capital, default in payment, pre-closure, creation of second charge on the security offered and repayment and recovery. The evaluation of the terms and conditions of lending is done in this section based on the ratings of the assisted units on each of the selected variables. As part of appraising, summated score of the views given by the selected units (hereinafter called terms and conditions score) on the seven dependent variables has been calculated. The average score of ratings of the units against each criterion in the evaluation process is given in Table 4.

Table 4 Score of views on terms and conditions

\begin{tabular}{|c|c|c|c|c|}
\hline Sl. No. & Criteria & Central value & $\begin{array}{l}\text { Actual } \\
\text { Score }\end{array}$ & Rank \\
\hline 1 & Promoters' Share & 3 & 3.068 & 1 \\
\hline 2 & Security Requirements & 3 & 2.158 & 5 \\
\hline 3 & Rate of Interest & 3 & 1.53 & 6 \\
\hline 4 & Penalisation for Default & 3 & 1.444 & 7 \\
\hline 5 & Pre Closure Premium & 3 & 2.186 & 4 \\
\hline 6 & $\begin{array}{l}\text { Restriction in Second Charge } \\
\text { Creation }\end{array}$ & 3 & 2.794 & 3 \\
\hline 7 & Repayment \& Recovery Norms & 3 & 2.886 & 2 \\
\hline & Total & 21 & 15.974 & . \\
\hline
\end{tabular}

Source: Primary data 
Figure 2 Error bars of terms and conditions score - industry wise

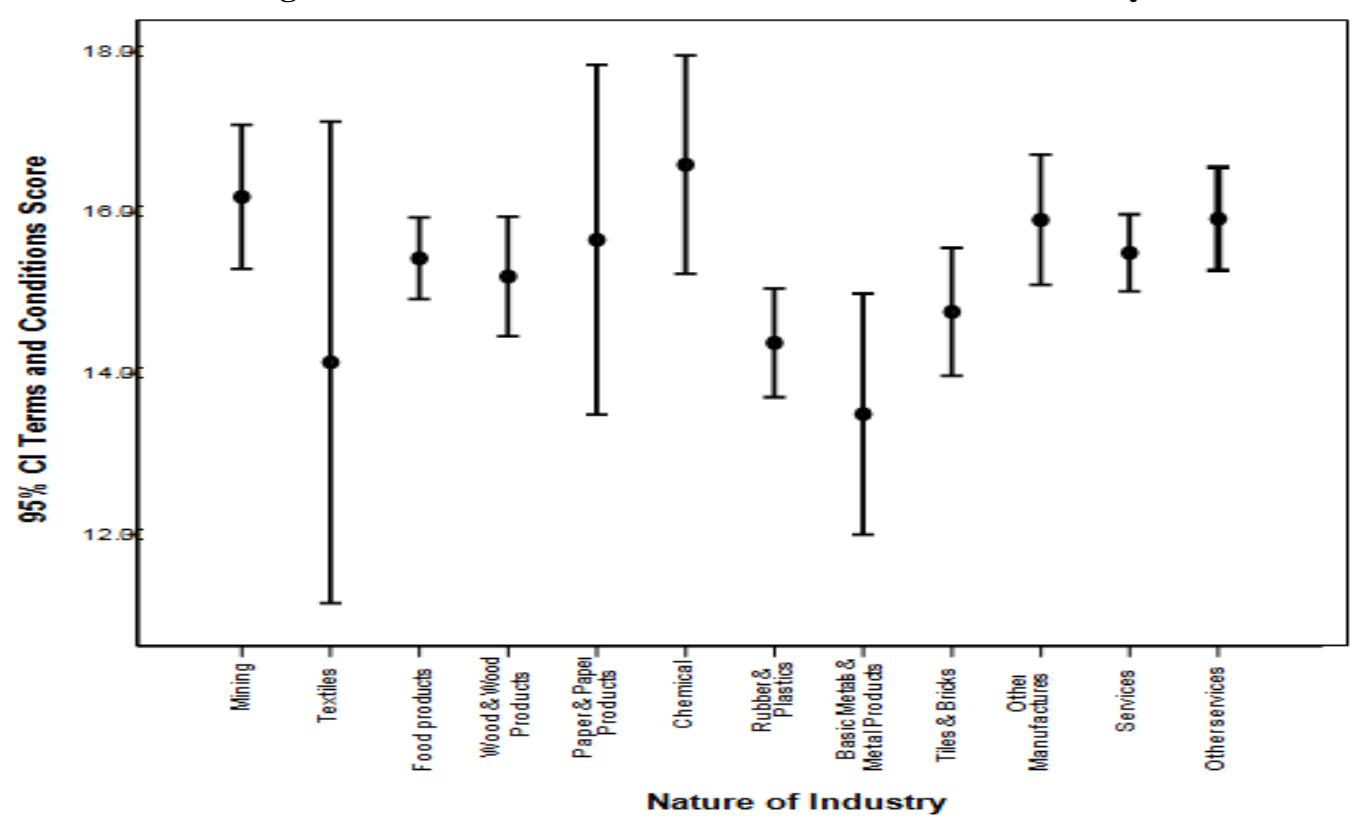

Table 5 ANOVA - terms and conditions score

\begin{tabular}{|c|c|c|c|c|c|}
\hline Source of Variation & $\begin{array}{c}\text { Sum of } \\
\text { Squares }\end{array}$ & df & $\begin{array}{c}\text { Mean } \\
\text { Square }\end{array}$ & F & P-value \\
\hline Between Groups & 215.269 & 11 & 19.570 & 3.047 & .001 \\
\hline Within Groups & 3134.593 & 488 & 6.423 & & \\
\hline Total & $\mathbf{3 3 4 9 . 8 6 2}$ & $\mathbf{4 9 9}$ & & & \\
\hline
\end{tabular}

Significant difference

The minimum possible value of terms and conditions score is seven, the maximum is thirty-five and the central value is twenty-one. The Error bars for the terms and conditions score at ninety-five per cent confidence level (Fig. 2), industry-wise, confirm that all the industries, without exception, gave lower rating to the terms and conditions imposed by the SFIs on the units. Thus, the hypothesis formulated for the study, the terms and conditions imposed by the SFIs are unfavourable to the industrial sector in the State, can be accepted. Significant differences were found industry-wise on views of units on terms and conditions (Table 5).

\section{Promoter's Share}

The SFIs usually limit the term loan assistance to a unit by insisting on a minimum promoter's capital requirement. This minimum share may vary from ten per cent to fifty percent of the project cost of the unit, depending on the nature of industry, track record of the promoter, security offered by the promoter, and above all the lending policy of the institution $\left(\mathrm{KFC}_{(\mathrm{b})}, 2005\right.$, pp. 1-15; $\left.\mathrm{KSIDC}_{(\mathrm{b})}, 2005\right)$. The Corporations, to ensure sustained and continued interest of the promoters in the project, normally insist upon the minimum promoters' capital. Promoter's capital requirement, being one of the primary conditions of lending, offers much flexibility (by relaxation) to the Corporations to welcome more entrepreneurs to start industries without affecting the quality of lending of the institution. Responding to these views of the units, the Corporations asserted that reasonable promoters' stake was inevitable for the successful conduct of the project and that any dilution in this respect might bring impoverishment. The views of the assisted units in this regard are quite good (score 3.068, rank 1) as it is just above the central value of the expected individual score. Considering the responses in total, though the majority of the units registered positive responses on the promoter's share, a significant number of units recorded disagreement, blaming it as high to very high, and difficult to afford. Therefore, any positive steps from the part of the Corporations to relax promoters' capital requirement, either through new schemes or revising the existing schemes, can certainly bring more genuine entrepreneurs to begin units.

\section{Security Requirement}

As part of the terms and conditions for availing term loans, in most of the cases, the Corporations insisted upon the provision of sufficient security by the loanees. The volume of security demanded by the SFIs is normally based on the nature of industry and promoters' capital commitment. Usually, the principal security is a first charge for the SFIs on the fixed assets of the unit. Additional collateral cover may also be demanded depending upon promoters' capital and nature of ownership of premises of the unit (owned or rented). Provision 
of security of sufficient worth satisfying the institutional requirement is a significant criterion for sanctioning loans from SFIs. As far as the loanees are concerned, provision of fixed assets of the unit as principal security does not pose any problem, but for additional collateral cover, they should pledge other or others' properties. The responses of the selected units concerning the security requirements of the Corporations as part of sanctioning loans reveal that the majority of the units in every industry considered the security requirements of SFIs to be high to very high and experienced difficulty to provide it (score 2.158, rank 5). While considering the burden of the promoters to provide collateral security in addition to the principal security, the demand for collateral security for sanctions may be deemed unwarranted. However, the Corporations were also of the view that relaxation of collateral security in lending might attract fictitious promoters to avail loans with marginally lower security. However, these arguments put forth by the Corporations convinced no one, and it was viewed like burning the house to chase the rats. Being industrial promotional agencies engaged primarily in lending, these Corporations could relax the present security requirement criterion so as to extend loans without collateral security.

\section{Rate of Interest}

Interest is levied as a fixed charge on the amount advanced and the rate at which it is levied is a matter of subjectivity of the lender, based on the agreement with the borrower. Regarding loanees, the payment of interest is a contractual obligation, failing which, it creates serious consequences of breach of contract. Further, it is a major factor of cost of production of goods and services with a distinguishing feature, consistency, with regard to its payment, regardless of the change in volume of production or service operation. So, the rate of interest on loans has a significant role in determining the overall cost of capital and thereby the profitability of the unit.

The responses of the selected units regarding the rate of interest charged by the SFIs confirm that, altogether, more than 90per cent of the units in every industry viewed the rate of interest charged by the Corporations as high to very high (score 1.53, rank 6). Regarding interest charges, the Corporations assert that the rates are fixed, taking into account the market conditions, cost of capital of the Corporations and the industrial promotion agenda of the State in general. These rates are subject to periodical revision according to the economic situations prevailing and changes in the policies of the government from time to time. The Corporations claim that they have been effecting reduction in interest rates during the post reform period overlooking their higher cost of capital. Moreover, they say that they have been offering a rebate in the form of reduction in the prevailing interest rate for promoting prompt payment by the loanees. Unfortunately, most of the loanees fail to take advantage of such a rebate for reasons beyond the control of the Corporations. However, the units have an altogether different view on this. They point out that though periodical revisions of rates were there, the Corporations had been limiting the advantage of such revisions (reduction in rates) only to that group of clients whose accounts remained prompt (very limited in number). The majority of the loanees of the KFC claim that if the advantages of revised rates from time to time were made applicable to them from the same dates on which such revised rates were put into effect, to those prompt clients, a considerable reduction in their accounts might have been effected, reducing their present liability. The units further argue that while they have been charged with penal interest for the defaulted period in addition to the denial of the rebate offered for prompt payment, the practice of the Corporations denying the revised interest rates (from time to time) to them until the arrears are cleared is gross injustice to them. As the arrears are unintentional and caused by circumstances expected in the conduct of industries, the loanees say that all penal practices should be abandoned. Moreover, most of the units were of the opinion that levying interest and its payment should be excluded for new units until the units started commercial production or service. Otherwise, the payment of interest during the promotion period out of the fund reserved for commitment in other assets, primarily for working capital, might get diluted, disrupting liquidity early in the beginning.

\section{Penalisation for Default}

The SFIs usually impose penalty on defaulters of loans by charging penal interest. The defence behind such a practice is to encourage and ensure prompt payment of interest and repayment of principal (in instalments) by the loanees. Moreover, they claim that the defaults on the part of the loanees can disrupt the budgeted cash flows of the Corporations, bringing uncertainty in the execution of planned regular activities. Therefore, the irregular servicing of loans always attracts penal charges. Like usual interest charges, the magnitude of penal charges has also a direct impact in amplifying the cost of production or operation and narrowing the profit margin of the assisted units. Responses regarding penalty imposed for arrears in repayment reveal that the majority of the units in every industry deemed it high to very high (score 1.444, rank 7). In this connection, most of the loanees reported that the arrears were unintentional, but caused by circumstantial inability and feeble financial position. Moreover, they said that the setting up of industrial units in Kerala, involved many risks causing variability in expected revenue and profit. Therefore, irregularity in servicing 
loans is inherent in industry. Incidence of penalisation rather than lending a hand in those situations, the loanees say, may further worsen the condition of the defaulter. As advancing loans and its repayments are parts of the operating cycle of the Corporations, irregularity in repayments as explained earlier may seriously affect the flow of the cycle. Above all, they say that the prudential norms by RBI on income recognition, asset classification and provisioning force them to insist up on prompt payment to avoid large-scale provisioning against profits for NPAs. Industries are generally prone to many kinds of risks and therefore have to struggle much to record success in their respective paths. Considering the industrial situation of Kerala, gaining success by units is a very strenuous effort. Comparing the performance of the State with many other states in India, several veterans seriously deliberating on the industrialisation of Kerala opined that the State's industrial growth continued to be tardy and halting (Subrahmanian, 1990, p. 2053; Thampi, 1999, p. 246; Thomas, 2005, p. 763). Therefore, a judicious application of penalisation for default is warranted in these situations for a State like Kerala.

The loan agreements of the SFIs with assisted units contain a provision to charge premium for premature closure of loans as part of discouraging loanees to end loan account before the period contracted. The SFIs follow the practice of charging 1 - 2per cent on the outstanding balance in the loan account as charges for premature closure. The institutional interest behind such a practice may be to restrict the premature closures of loan accounts by opting for alternative sources. The views of the loanees regarding the size of such premium and the practice of charging it as unfavourable (score 2.186, rank 4). Responding to these views of the loanees, the Corporations replied that sanctioning of loans and allocation of the funds required for that were part of longterm decisions involving cost of capital. Being non-banking financial institutions, the Corporations said that they could not make use of funds for short periods and therefore unexpected inflows in the form of premature closure of loans could get productively employed only after one or two months. The pre-closure premium, in their view, was charged as part of compensating such losses resulting from the non-utilisation of the amount for some period. And, there was no question of denial of any right of the loanees. Loanees more often go for premature closures to take advantage of the benefits from alternative sources. Such a decision is usually based on comparative analyses of the available alternatives and identification of incremental benefits attached to the alternatives. While computing such incremental benefits, it is quite logical to include the premium for premature closure of existing source of capital (payable to SFIs) as one of the costs of such alternatives and if the alternatives still weigh more in the matter of benefits, opt for the best of such alternatives. Then the grievance of loanees in this respect can be minimised. Even so, there appears the necessity of taking a fresh look at the whole thing.

\section{Restriction in Further Creation of Charge}

Usually, the SFIs create a first charge on the fixed assets of the assisted units and other properties offered as collateral security. As and when the assisted units go for raising working capital finance or additional finance from an agency other than the SFIs, it may be quite natural to provide sufficient security to them also. In such cases, the promoter may offer the same property or properties (offered as security to SFIs) as security to the other agency with the intention of creating a second charge for them with the consent of the SFIs. Normally, the provision for such type of arrangement is part of the loan agreements of the SFIs and it is the very sense of duty of the Corporations to co-operate with such processes. The opinions of the units in this regard shows the uneasiness in this respect (score 2.794, rank 3). The creation of second charge on the property offered as security to SFIs, as part of raising further advances from other agencies, usually does not make any insecurity to the Corporations and therefore, they welcomed it within the scope of loan agreements, policies and procedures. Any negative response in this regard, the Corporations blamed, might be because of the ignorance of the entrepreneurs regarding the formalities in this regard and the unwillingness to comply with those formalities. Anyhow, it is noteworthy here that, such type of anomalies on genuine grounds, if any, can be avoided if customer care is strengthened more.

\section{Repayment and Recovery Norms}

The SFIs usually design a suitable repayment pattern for each client within the limits of their policies and the requirements of the borrower. The pattern for each unit is planned, considering the nature of industry, risk involved in the business, length of gestation period required, term required for repayment, provision for rescheduling repayment and the facility for pre-closure. As the pattern of repayment of loan has a lot to do in the speedy and prompt amortisation of loans, it demands reasonable homework to plan. The pattern so designed becomes part of the loan agreement, as its acceptance by the borrower is a necessity. Adequate time for servicing the loans, out of earnings of the assisted units, ought to be given for the effectual and well-organized utilisation of the assistance. The time allowed by the Corporations for servicing the debt varies from scheme to scheme, industry to industry, and from purpose to purpose. Usually, the SFIs allow a repayment period of five to ten years, including three to twenty-four months' initial moratorium. Adequate time span for repayment will reduce the instalment-wise monetary burden and may give adequate cover for such payments out of the earnings 
of the unit. The industry-wise replies of the units regarding repayment pattern reveal that the majority of the units in every industry deemed the pattern to be satisfactory to good score (2.886, rank 2). Contrary to the above, a significant number of units in every industry deemed the pattern to be poor to very poor.

Most of the loanees opined that the monetary burden on servicing the loans (interest and principal) in earlier years was found difficult to afford as it was much higher in earlier years and lower in later years. This is true because, when the loan amount is amortised in equal instalments over the sanctioned period, the principal component in each instalment remains constant and the interest component fluctuates. Obviously, the interest burden declines over time, whereas the principal repayment remains constant and the debt service burden (interest plus principal component) would stand comparatively higher in earlier years. Conveniently, the units opt for lesser monetary burden in earlier years and higher in later years as, they say, the initial years are crucial with the burden of preliminaries. Therefore, if the payments take the reverse order, lesser monetary burden in earlier years and higher in later years of the loan, it will be more convenient.

\section{Conclusion}

Industrial finance institutions in India have been facing problems of structural competency to withstand in the market driven scenario invoked after the introduction of economic reforms in the country since 1991. The SFCs and SIDCs at State level have been facing declining lending volumes and plummeting significance. The claims of the institutions regarding their change in attitude and industrial promotion outlook failed to deliver goods in the post reform era. Even though many of these institutions are ISO certified, their lending operations are subject to much criticism. The present study about the institutions in Kerala gives empirical evidences for the cumbersome procedures and unviable terms and conditions in the lending operations. Being institutions of national importance, the very survival and efficient functioning of these kinds of institutions are of inevitable to bring healthy small and medium industrialisation in the country. These institutions cannot be replaced by commercial banks and new generation institutions which stand with varied operational agenda. Being institutions to be proactive to industrialisation and development, the existence of these institutions should be ensured with efficient reorganisation and protective government support to pave means for micro, small and medium entrepreneurs.

\section{References}

[1] Datar, M.K. 1999. DFIs in an Era of Developing Capital Markets. Economic and Political Weekly, 34(25).

[2] Ganesh, C. 1993. Role of State Financial Corporations in Financing Small Industries: Ph.D. Thesis, University of Kerala.

[3] Gupta, R.K. 1993. Development Banks and Industrial Development. New Delhi: Deep \& Deep Publications.

[4] IDBI. 2004. Report on Development Banking in India - Vol. I. Mumbai: Industrial Development Bank of India.

[5] IDBI. 2004. Report on Development Banking in India - Vol. II. Mumbai: Industrial Development Bank of India.

[6] Jestus, J. 1996. Financial Management of Small Scale Industries in Kerala: Ph. D. Thesis, University of Kerala.

[7] $\mathrm{KFC}_{(\mathrm{a})}$ 2005. Annual Report 2005. Thiruvananthapuram: Kerala Financial Corporation.

[8] $\mathrm{KFC}_{(\mathrm{b}) .}$ 2005. KFC - Schemes. Thiruvananthapuram: Kerala Financial Corporation.

[9] Koshy, Thomas. 1992. Role of Non Banking Financial Institutions in the IndustrialDevelopment of Kerala: Ph. D. Thesis, University of Kerala.

[10] KSIDC $($ (a). Annual Report, 1995-2005. Thiruvananthapuram: Kerala State Industrial Development Corporation.

[11] $\operatorname{KSIDC}_{(\mathrm{b}) .}$ 2005. Kerala State Industrial Development Corporation Offices, Thiruvananthapuram and Ernakulam.

[12] Mohan, Rakesh. 2004. Finance for Industrial Growth: Reserve Bank of India Bulletin, 2004.

[13] Nunnally, J.C. 1978. Psychometric Theory (2nd edition). New York: Mc Graw Hill.

[14] Pathak, Bharati V. 2003. Indian Financial System: Pearson Education (Singapore) Pvt.Ltd., India Branch.

[15] Patil, R.H. 2001. Industrial Finance and Capital Market - Changing Scenario. Economic and Political Weekly, 36(4).

[16] Subramanian, K.K. 1990. Development Paradox in Kerala - Analysis of Industrial Stagnation (Special Article), Economic and Political Weekly, 25(37).

[17] Thampi, M.M. 1999. Economic Liberalisation and Industrial Development in Kerala: Challenges to New Investments, in Prakash, B.R. (ed) Kerala's EconomicDevelopment: Issues and Problems. New Delhi: Sage Publications India Pvt. Ltd.

[18] Thomas, Jayan Jose (2005). Kerala's Industrial Backwardness: A Case of Path DependenceinIndustrialisation?.World Development, 33(35).

\section{Footnotes}

${ }^{1}$ The different committees which probed the matter of industrial finance and recommended the setting up of industrial banks/special financial institutions for industrial credit were: Industrial Commission- 1916, External Capital Committee-1924, Central Banking Enquiry Committee-1931 (Panda and Dash, 1991, pp. 128-130).

${ }^{1}$ Kerala is a narrow stretch of land located along the south-west coast of the Indian subcontinent comprising a total land area of 38,863 sq. km. and a total population of 38.84 million (Govt. of Kerala, 2005, pp. 28-41. The penal charge for the default is 2per cent p.a. for the defaulted amount for the defaulted period. 